\title{
In reply: Confirmation of endotracheal tube depth using ultrasound in adults
}

\author{
William P. Mckay, MD • Andrew Wang, MD • \\ Kinsha Yip, MD · Mateen Raazi, MBChB
}

Received: 23 February 2015/Accepted: 3 March 2015/Published online: 12 March 2015

(C) Canadian Anesthesiologists' Society 2015

\section{To the Editor,}

We are grateful for the interesting comments and important points raised by $\mathrm{Li}$ et al. ${ }^{1}$ in reference to our recent study. ${ }^{2}$ Our endotracheal tubes (ETTs) had a tip-toproximal-cuff distance of $5.5 \mathrm{~cm}$ for females and $6 \mathrm{~cm}$ for males. We measured the distance from ETT tip to vocal cords, as reported in an earlier study, but we chose not to report these results in the current study because we could not devise a method to validate the measurement. This is because bronchoscopic measurement involves marking depth when the bronchoscope light shines most brightly through the cricothyroid membrane with the room lights turned off. ${ }^{3}$ This endpoint may be somewhat variable and subjective. The unvalidated measurement to determine ETT depth indicated that the ETT cuff was partly within the vocal cords in four of 43 cases using ultrasound and in 12 of 43 cases when measured at the teeth (i.e., the measurement method used in the studies $)(P=0.05$; Fisher's exact test). ${ }^{2,3}$

We are not experienced at visualizing the cuff with ultrasound, as mentioned by $\mathrm{Li}$ et al., and it does raise several questions. For example, can an air-filled cuff be seen, or must the cuff be filled with liquid? Which visualization technique is optimal, the transverse or the longitudinal view or both views, and which probe is best? How much training and practice is required to ensure consistent visualization of the ETT cuff? Li et al. refer to a

\footnotetext{
W. P. Mckay, MD (ه) · A. Wang, MD · K. Yip, MD ·

M. Raazi, MBChB

Department of Anesthesiology, Perioperative Medicine and Pain

Management, University of Saskatchewan, Saskatoon, SK,

Canada

e-mail: william.mckay@saskatoonhealthregion.ca
}

study that reported a 50-min training period for accurate identification of a saline-filled ETT cuff. ${ }^{4}$

Visualizing the cuff at the sternal notch may or may not guarantee correct ETT placement. In particular, this assumes that the carina is at the level of the manubriosternal joint (or sternal angle), an anatomic relationship that has been dogma for so long that we were unable to find its source. A study from China, where the majority of the population is shorter in stature than the Canadian population, found the mean (SD) height of the manubrium to be $4.4(0.4) \mathrm{cm}$ for females and $5.1(0.4) \mathrm{cm}$ for males. Thus, with the measured distal-cuff-to-tip distance on our ETTs of $2.2 \mathrm{~cm}$ for females and $2.5 \mathrm{~cm}$ for males, the ETT tip is clear of the carina even in those with a manubrium shorter than 2 SDs below the mean. Nevertheless, a study of ballottement of the cuff in the sternal notch appears to have found 20 of 44 ETT tips closer than $2.5 \mathrm{~cm}$ from the carina. ${ }^{5}$

A clear view of the cords with direct or video laryngoscopy for intubation helps prevent incorrect placement by simply meticulously visualizing the top of the cuff passing approximately $2.5 \mathrm{~cm}$ through the cords. Nevertheless, the view is quite commonly obstructed; consequently, for these patients, future studies should seek to confirm that the carina is consistently found at the level of the sternal angle and also to find rapid and reliable methods to locate the cuff relative to the manubrium.

Finally, the commercial ETTs we use may not be optimally designed. For example, considerable published research went into the design of a modern cuffed pediatric ETT, ${ }^{6}$ but there is no way of knowing whether similar efforts went into the proprietary design of adult ETTs. Our research (combined data from two studies; ${ }^{2,3} n=133$ ) suggests considerable variability in the mean (SD) length of the adult airway from cords to carina of $12.6(1.9) \mathrm{cm}$ 
with a range of $6.7-17.1 \mathrm{~cm}$. There is little room for error in depth placement in patients with shorter airways, especially when $5.5-6 \mathrm{~cm}$ is taken up by the cuff. Thus, it is desirable to design a cuffed ETT with optimal dimensions that can incorporate the following conflicting goals: the shortest cuff that is still unlikely to produce an area of concentrated pressure on tracheal mucosa, and the shortest distal-cuff-to-tip distance that is still unlikely to result in cuff herniation over the tip. ${ }^{6}$ Much research is still necessary to assure that intubation is the safest possible for our patients.

Conflicts of interest None declared.

\section{References}

1. Li Y, Wang J, Wei X. Confirmation of endotracheal tube depth using ultrasound in adults. Can J Anesth 2015; 62: this issue; DOI: 10.1007/s12630-015-0359-2.
2. McKay WP, Wang A, Yip K, Raazi M. Tracheal ultrasound to assess endotracheal tube depth: an exploratory study. Can J Anesth 2015; DOI:10.1007/s12630-015-0313-3.

3. McKay WP, Klonarakis J, Pelivanov V, O'Brien JM, Plewes C. Tracheal palpation to assess endotracheal tube depth: an exploratory study. Can J Anesth 2014; 61: 229-34.

4. Uya A, Spear D, Patel K, Okada P, Sheeran P, McCreight A. Can novice sonographers accurately locate an endotracheal tube with a saline-filled cuff in a cadaver model? A pilot study. Acad Emerg Med 2012; 19: 361-4.

5. Pollard RJ, Lobato EB. Endotracheal tube location verified reliably by cuff palpation. Anesth Analg 1995; 81: 135-8.

6. Weiss $M$, Dullenkopf A, Bottcher $S$, et al. Clinical evaluation of cuff and tube tip position in a newly designed paediatric preformed oral cuffed tracheal tube. Br J Anaesth 2006; 97: 695-700. 